\title{
La larga lucha por la emancipación de las mujeres. Carmen Baroja y Nessi, Zenobia Camprubí Aymar y María Teresa León Goyri
}

\author{
Julia Varela Fernández \\ Universidad Complutense de Madrid. Facultad de Ciencias de la Información. \\ Departamento de Sociología VI \\ jvarela@fis.ucm.es
}

\section{Resumen}

Los escritos autobiográficos de Carmen Baroja, Zenobia Camprubí y María Teresa León nos permiten seguir de cerca el enorme esfuerzo que realizó un importante colectivo de mujeres de la burguesía liberal española de la primera mitad del siglo XX para romper con el dispositivo de feminización, dejar de ser el sexo débil y alcanzar una mayor autonomía personal y profesional. El análisis sociohistórico de las trayectorias de estas tres mujeres muestra que, en cierta medida, pudieron desasirse de los lazos de sujeción atados, y bien atados, por las principales instituciones de socialización establecidas en unas sociedades en las que imperaba un fuerte desequilibro de poder entre las clases y entre los sexos. Esa ruptura fue posible gracias a su capital económico y cultural de origen, a los trabajos que realizaron, a las asociaciones de mujeres de las que formaron parte, a las redes sociales en las que se apoyaron, así como a su resistencia y tenacidad frente a la dominación masculina. Si se exceptúa la época de la Segunda República, ni los gobiernos, ni la gran mayoría de los varones, empezando por los de su entorno más próximo, fueron cómplices en sus proyectos para lograr una mayor emancipación.

Palabras clave: configuración social; dispositivo de feminización; instituciones de socialización; historias de vida; asociaciones de mujeres; desequilibrio de poder; capital altruista.

\section{Abstract. The long struggle for women's emancipation: Carmen Baroja y Nessi, Zenobia Camprubi Aymar and María Teresa León Goyri}

The autobiographies of Carmen Baroja, Zenobia Camprubí and María Teresa León provide a deep understanding, in the context of the first half of the twentieth century, of the enormous effort made by a significant group of women from the Spanish liberal bourgeoisie to break with the feminization device, and hence with the weaker sex condition, which enabled them to achieve greater personal and professional autonomy. A socio-historical analysis of these women's life trajectories shows that, to some extent, they were able to free themselves from the bonds of subjection in a society where a strong imbalance of power prevailed between classes and sexes. As we argue in this paper, some of the factors which 
enabled such a transformation were the economic and cultural capital of origin, the professional activities they engaged in, their participation in associations and women collectives, the social networks which supported them, and their resistance and tenacity against male domination. With the exception of the Second Spanish Republic, neither governments nor the vast majority of men from their surroundings joined or were partners in their projects to achieve greater emancipation.

Keywords: social configuration; feminization device; institutions of socialization; life stories; women's associations; imbalance of power; altruistic capital.

\author{
Sumario \\ 1. Introducción \\ 5. Reflexiones finales: el capital altruista, \\ 2. Una nueva querella de las mujeres \\ una nueva dimensión del capital social \\ 3. Orígenes y destinos \\ Referencias bibliográficas \\ 4. Las vanguardias artísticas \\ y la cultura popular
}

\title{
1. Introducción
}

Este artículo se basa en los escritos autobiográficos de tres mujeres de una misma generación que vivieron de forma intensa el final de la dictadura de Primo de Rivera, la Segunda República, la Guerra Civil y los tiempos del exilio durante el franquismo: Carmen Baroja y Nessi, Zenobia Camprubí Aymar y María Teresa León Goyri. Las dos primeras nacieron a finales del siglo XIX y la tercera, a comienzos del XX. La elección del estudio de estas tres mujeres se debe, en primer lugar, a la riqueza y a los matices que ofrece la interpretación de textos biográficos contextualizados. En este sentido, existe ya una tradición asentada que se sirve de material autobiográfico en los estudios del género (Varikas, 1988; Gemis, 2008). En segundo lugar, los textos autobiográficos de estas tres mujeres ofrecen, desde posiciones políticas distintas - que van desde un liberalismo un tanto conservador (Carmen), hasta el partido comunista (María Teresa), pasando por un liberalismo progresista (Zenobia)_, visiones diferentes de la vida y de los procesos de subjetivación, lo que facilita un análisis comparativo. En tercer lugar, las tres, en alguna medida, vivieron a la sombra de varones famosos que contribuyeron a hacerlas invisibles. Carmen Baroja vivió con sus hermanos Pío y Ricardo Baroja; Zenobia Camprubí, con su marido Juan Ramón Jiménez, y María Teresa León, con el poeta y dramaturgo Rafael Alberti. Pío Baroja, Juan Ramón Jiménez y Rafael Alberti estuvieron situados en el centro del campo literario de su tiempo. Eclipsadas por el protagonismo de estos artistas y escritores ilustres, parecía necesario contribuir a sacarlas a la luz, aproximarnos a la vida y la obra de tres mujeres que también escribieron, y ello para romper un tendencioso olvido y para enriquecer la memoria histórica. A todas estas razones, que justifican la realización de este estudio, se añade una última que 
es para mi importante, pues este artículo pretende ser la prolongación lógica de un libro en el que traté de mostrar cómo, a través del dispositivo de feminización, se gestó el encierro de las mujeres en el hogar, es decir, su domesticación y su exclusión del espacio público (Varela, 1997). A mi juicio, frente a la tesis de una dominación masculina, que reenvía a una especie de poder patriarcal universal instaurado desde tiempos remotos, era importante tratar de explicar cómo y por qué surgió en la transición de la edad media a la edad moderna lo que entonces denominé el dispositivo de feminización, entendido éste como un sistema de instituciones, prácticas y saberes que contribuyeron a conferir a las mujeres una nueva naturaleza subordinada a los varones, así como funciones acordes con esta nueva identidad impuesta. Los poderes no son, sin embargo, uniformes ni eternos, y esto es lo que se va abordar ahora aquí: cómo las luchas de las propias mujeres contribuyeron a romper, en el siglo XX, de forma generalizada y en los países occidentales europeos, el corsé institucional que se les había impuesto durante siglos. La hipótesis de partida es que una lectura detenida de los textos autobiográficos de Carmen Baroja, Zenobia Camprubí y María Teresa León, tres mujeres que provienen de la burguesía liberal española con un elevado capital cultural, integradas en familias de clases medias con una posición social acomodada, debería ayudarnos a comprender cómo ellas, y con ellas un más amplio colectivo de mujeres que compartían una posición social similar, lograron resistir, ir más allá de los cánones que entonces regían la vida femenina, para trascender en cierta medida el sistema de normas y prácticas que las destinaban exclusivamente a ser buenas madres y esposas hacendosas.

Contamos con valiosos trabajos, especialmente realizados por historiadoras, tales como enciclopedias, que recogen la vida de mujeres españolas (Tavera, 2000), y también con historias de mujeres y estudios bibliográficos. Mary Nash y Marisa Ferrandis, por ejemplo, ya realizaron, a principios de los años noventa, un mapa historiográfico en el que señalaron las distintas tendencias entonces existentes (Nash y Ferrandis, 1991). Algunas de dichas contribuciones han servido de ayuda para la elaboración de este texto, sobre todo aquellas que analizan la vida de las mujeres españolas en distintos periodos del siglo XX: años veinte, Guerra Civil, exilio, franquismo y transición democrática. Por ejemplo, algunos libros de Mary Nash (Nash, 1999), Shirley Mangini (Mangini, 2001), Maria Teresa Gallego o de la asociación Mujeres en la Transición Democrática (1999), así como también algunas investigaciones basadas en materiales autobiográficos (Domínguez, 2009). Por lo general, en estos trabajos, así como en otros ya clásicos de sociología del género, entre ellos los de Marina Subirats, Inés Alberdi, Rita Randl Philipp y Constanza Tobío, se pone de relieve que las mujeres han contribuido a hacer la historia, aunque generalmente no sean reconocidas suficientemente por ello. En dicho sentido, este artículo es afín a la perspectiva de la historia de las mujeres, pero también se diferencia de este ámbito de investigación, pues, desde el punto de vista epistemológico y metodológico, se inscribe en el registro de la sociología histórica comparativa, es decir, de la genealogía. 
La genealogía se diferencia de la historia, pues, aún sirviéndose del mismo tipo de fuentes y de los materiales sobre los que trabajan los historiadores, los utiliza de forma distinta. Robert Castel puso bien de manifiesto las diferencias que existen entre la sociología y la historia, cuando afirmó la especificidad de la genealogía. Señaló que el análisis genealógico debe reposar sobre el respeto a los datos históricos que nos proporcionan los historiadores, pero reordenando los materiales en función de problemas acuciantes del presente y construyendo un relato que esté articulado a partir de determinadas categorías sociológicas (Castel, 1977). En consecuencia, no solo es importante mostrar las trayectorias de vida de estas tres mujeres, sino también hacer de ellas un referente que nos permita comprender mejor el presente. Por otra parte, para entrecruzar las historias de vida de estas tres mujeres con las condiciones sociohistóricas en las que nacieron y vivieron, he partido del concepto sociológico de dispositivo de feminización. Y con el fin de organizar los materiales obtenidos de las autobiografías de Carmen Baroja y Nessi, Zenobia Camprubí Aymar y María Teresa León Goiry, así como los datos secundarios procedentes de trabajos realizados sobre ellas, me he centrado en tres dimensiones que reenvían a las variables que, en la mayoría de los trabajos sociológicos, sirven para determinar una posición social y estructurar las trayectorias de vida: capital cultural, capital económico y capital social, en términos de Pierre Bourdieu, o, más comúnmente, educación, trabajo y sociabilidad. El capital social, o la sociabilidad, han sido considerados teniendo en cuenta distintos indicadores, desde las asociaciones de mujeres hasta las relaciones con las vanguardias artísticas y la cultura popular. Desde el punto de vista metodológico, este trabajo se inscribe en la perspectiva que han desarrollado científicos sociales tales como Robert Castel, Michel Foucault, Norbert Elias, Werner Sombart, Pierre Bourdieu, Richard Sennett, Anthony Giddens y Judith Walkowitz.

\section{Una nueva querella de las mujeres}

Antes de abordar las tres dimensiones anteriormente mencionadas, conviene caracterizar, aunque sea brevemente, el marco histórico en el que las protagonistas de nuestro artículo nacieron y vivieron, pues sus vidas solo cobran pleno sentido en su contexto histórico.

A finales del siglo XIX, tras la Comuna de París, se produjeron transformaciones significativas en toda Europa. Los gobiernos de los países occidentales empezaron a poner en marcha un incipiente estado social que reconocía algunos derechos básicos de las clases trabajadoras. La entrada de los partidos socialistas en los parlamentos supuso una integración parcial de los intereses y las reivindicaciones de las clases populares en el juego democrático. En el campo intelectual, uno de los cambios importantes consistió en el paso de Marx a Freud. Tendencialmente, la superación de las dominaciones de clase se vio sustituida, en el marco de un incipiente estado social, por la búsqueda del bienestar personal. A partir de ahora, el inconsciente va a ser el encargado de explicar no sólo la dinámica de la vida individual, sino también la de la vida social. Así fue como la cuestión social 
empezó a quedar relegada a un segundo plano, mientras que la cuestión sexual y la cuestión femenina pasaron a ocupar el primer plano.

En la sociedad española de la Restauración, una sociedad que se caracterizaba por la existencia de desigualdades notables entre el mundo rural y el urbano, al igual que entre los distintos grupos y clases sociales, las desigualdades de género estaban también a la orden del día. Renació de nuevo la querella de las mujeres, que conoció en España diversas manifestaciones. En los debates sobre el estatuto de las mujeres, participaron conocidos varones de la época; por ejemplo: Gregorio Marañón, en un libro titulado Maternidad y feminismo: Tres ensayos sobre la vida sexual, mantuvo la influyente teoría de que los sexos son a la vez diferentes y complementarios. Marañón pretendía legitimar y reforzar científicamente el papel de las mujeres como amas de casa, esposas y madres. Por otra parte, el premio Nobel de Medicina, Don Santiago Ramón y Cajal, descubridor del funcionamiento de las neuronas, reaccionó en contra de los derechos políticos y profesionales que estaban reclamando las feministas, ya que «la divergencia física y moral de los sexos es obra milenaria de la naturaleza y base de la prosperidad de la especie» (VVAA, 1994: 376, 408-409). Una cierta misoginia se dejaba traslucir también en algunos escritos de José Ortega y Gasset, Rafael Cansinos Assens, Jacinto Benavente y muchos otros pensadores y escritores. En este aspecto, España no se diferenciaba demasiado de lo que sucedía en otros países europeos.

Las tesis sexistas coexistían con el racismo y el darwinismo social, incluso eran compartidas por algunos representantes de los grupos menos conservadores. En general, seguía dominando el estereotipo de que las mujeres estaban destinadas al cuidado de la casa y a la procreación, mientras que los varones estaban destinados a conquistar y a recrear el mundo, en suma, a ser los protagonistas de la historia. En muchos de los escritos de la época, seguían resonando las palabras escritas en el siglo XVI por el humanista valenciano Luis Vives: "Para la mujer, la casa hará las veces de toda la República».

Estas visiones predominantemente negativas de las mujeres, reforzadas por el positivismo darwinista y por la ofensiva de la Iglesia católica contra el socialismo, encontraron, sin embargo, resistencias. Algunas mujeres de la burguesía comenzaron a hacerse visibles en el espacio público y asumieron tareas que hasta entonces se consideraban masculinas, a la vez que criticaron la escasa educación que recibían y la falta de oportunidades para acceder a actividades que les proporcionasen autonomía mental y económica. Se pusieron en marcha nuevos salones literarios dirigidos por mujeres, entre ellos los de Carmen de Burgos (1867-1932) o los de Concha Espina (1869-1955). Empezaron a constituirse algunas asociaciones de mujeres; por ejemplo: en 1897, se creó, por iniciativa de mujeres republicanas y laicas, la Asociación General Femenina. Otras asociaciones de mujeres estuvieron más ligadas a los partidos políticos; por ejemplo: la Sociedad Autónoma de Mujeres, que se instituyó en Barcelona en 1899, y el Grupo Femenino Socialista, que se fundó en Madrid en 1906. En ese mismo año, se creó la Junta de Damas de la Unión Iberoamericana de Madrid, cuya vicepresidenta era Concepción Gimeno, una escritora y periodis- 
ta muy activa. Se publicaron distintas revistas, entre las que cabe citar La mujer (1871), dirigida por Faustina Sáez de Melgar, quien, con la ayuda de Fernando de Castro, había fundado, en 1868, el Ateneo Artístico y Literario de Señoras, así como La Ilustración de la Mujer (1872), dirigida por Sofía Tartilán. Todas estas asociaciones y publicaciones abogaban por la emancipación femenina, así como por un ideal de educación progresista y laico. Un poco más tarde, en 1919, por iniciativa de Celsa Regis, se reunieron varias mujeres de la burguesía en el despacho de María Espinosa de los Monteros y fundaron la Asociación Nacional de Mujeres Españolas (ANME). Surgió, así, una nueva e importante institución formada por un grupo heterogéneo de mujeres: Benita Asas, Clara Campoamor, Elisa Soriano, María de Maeztu, Victoria Kent y otras que se habían significado en distintos medios en favor de la emancipación femenina. Esta asociación tuvo un peso importante en la década de 1920.

Desde finales del siglo XIX y principios del XX, algunas mujeres, entre ellas, Soledad Gustavo (1896, 1899), la madre de Federica Montseny, Margarita Nelken (1919), Carmen de Burgos (1927), Teresa Claramunt (1905) o Clara Campoamor confirieron en sus libros una importancia especial a la educación, al trabajo y a la personalidad jurídica de las mujeres, al considerar que, sin formación, sin trabajo y sin leyes igualitarias, ellas no podrían alcanzar ni la independencia económica, ni poseer instrumentos adecuados para intervenir en los distintos espacios de la vida social y política. Lucharon, por tanto, a favor de la reforma del Código Civil. Además, aconsejaron a las mujeres, tanto a las proletarias como a las burguesas, que se asociasen para defender sus intereses, especialmente los laborales, y fueron muy críticas con los sindicatos de acción católica, que atraían a muchas mujeres, por considerar que eran los que menos estimulaban el trabajo femenino fuera de casa ${ }^{1}$. Vemos, por tanto, que no era nada fácil, en el primer tercio del siglo XX, para las mujeres de las distintas clases sociales, incluso para las de la burguesía liberal, gozar de autonomía personal, y menos aún de independencia económica, pues si eran solteras aún estaban bajo la potestad del padre, y si se casaban dependían de la del marido, que era, por ley, el cabeza de familia encargado de gestionar los bienes. Las condiciones sociales, políticas y culturales en las que vivían la mayoría las condenaba, además, a una falta de autonomía moral. Se explica, así, que muchas mujeres se dejasen arrastrar por el espejismo de que el matrimonio era su única salida.

\section{Orígenes y destinos}

En la lucha de las mujeres por la emancipación, desempeñaron un papel relevante las tres dimensiones a las que me he referido anteriormente y que paso a exponer con más detenimiento.

1. Entre las feministas pioneras, resulta obligado mencionar a Concepción Arenal y a Emilia Pardo Bazán. Ambas defendieron, y mostraron con su ejemplo, la capacidad de las mujeres para autogobernarse y ejercer funciones de gobierno, y reclamaron para ellas una educación que les permitiese ser autónomas, que no estuviese exclusivamente dirigida a estar al servicio de los demás. 


\subsection{Una educación «ilustrada»}

A través de los escritos autobiográficos de Carmen, Zenobia y María Teresa, se muestra que las mujeres de la burguesía liberal española recibían, en los primeros años, una educación bastante parecida a la de sus hermanos. Pero se pone también de manifiesto que, cuando crecían, mientras que la educación de sus hermanos, como afirma Zenobia, estaba encaminada a que adquiriesen una formación para ejercer una profesión que les permitiese valerse por sí mismos en la lucha por la vida, esto no sucedía con las hijas, pues se suponía que ellas estarían protegidas por los varones, ya fuese por el padre, los hermanos o el marido. La discriminación por razones de género empezaba, sin embargo, en el seno de las familias. Carmen Baroja describe así el clima que reinaba entonces en muchos hogares españoles de las clases medias:

La moral de mi casa, muy a la española, era por demás rígida para mí en cosas pueriles y sin importancia, y muy laxa para mis hermanos en cosas que yo, ya entonces, consideraba importantes. Luego, después de casada, esta moral todavía se acentuó más, y ya no tuve derecho más que a hacer mis labores domésticas y llevar la carga de muchísimas cosas. (Baroja, 1998: 69)

La primera educación formal se desarrolló, en el caso de Carmen y María Teresa, en colegios de monjas, como era habitual en la época, mientras que a Zenobia la educaron su madre, su abuela materna y preceptores particulares sin salir de casa. Además de aprender a leer, así como nociones de historia y geografía, la música, la caligrafía y los idiomas eran tres aprendizajes importantes para una señorita de las familias distinguidas de la época, a los que se sumaba el de las primorosas labores de aguja. Julio Caro Baroja afirma, en Los Baroja, que la educación que recibió su madre se diferenciaba de la tradicional que recibían otras mujeres, pues estaba menos llena de gazmoñerías y ridiculeces: «Así mi madre, de niña, aprendió muy bien el francés y bastante inglés, le enseñaron música con mucho aprovechamiento y luego una porción de cosas de las que eran novedades por entonces» (Caro, 1997: 60).

Desde finales del siglo XIX, empezaron también a gestarse nuevos modelos educativos, de tal modo que hubo niñas y jóvenes que no se educaban en los colegios de monjas, ni eran educadas por preceptores, sino que se educaban en escuelas racionalistas ligadas a los anarquistas, ideario que rigió también la educación que le proporcionó su madre a Federica Montseny o en los colegios de la Institución Libre de Enseñanza (ILE), como pone de relieve María Teresa León cuando habla tan admirativamente de la que recibía su prima Jimena Menéndez Pidal, y en algunas escuelas que abrieron los socialistas. Todas estas nuevas instituciones educativas se basaban en las llamadas nuevas pedagogías, de corte rousseauniano, pedagogías que preconizaban la coeducación y una enseñanza activa y participativa, fundada en la razón y en la ciencia, tal como entonces se entendían.

Eran, no obstante, muy pocas las mujeres que tenían estudios universitarios a principios del siglo XX. Entre esta minoría, se encuentra, por ejemplo, 
María Goyri, la tía de María Teresa León, que pudo ingresar en la universidad superando toda una serie de obstáculos. Es preciso recordar que, casi a finales del siglo XIX, el 90\% de las mujeres no sabían leer ni escribir, y que su acceso a la universidad no se produjo hasta 1911, momento en el que se les permitió realizar estudios secundarios y universitarios sin contar con la autorización de sus padres ni de las autoridades académicas. Emilia Pardo Bazán fue la primera catedrática universitaria con el voto del claustro en contra, pero conviene tener, además, en cuenta que las mujeres que cursaban estudios universitarios solían acceder sobre todo a carreras femeninas, carreras consideradas en cierto modo una prolongación de las funciones tradicionales de las mujeres en el hogar: maestras de párvulos, parteras, enfermeras, trabajadoras sociales, farmacéuticas. Otro rasgo a destacar es que la mayoría de estas mujeres universitarias abandonaba definitivamente el trabajo con mucha frecuencia cuando contraía matrimonio.

\subsection{Asociaciones de mujeres}

Nuestras tres protagonistas formaron parte activa, cuando eran jóvenes, de asociaciones de mujeres, concretamente de la Residencia de Señoritas y del Lyceum Club, ambas dirigidas por María de Maeztu. La Residencia de Señoritas se fundó en 1915 y estuvo muy ligada a la Residencia de Estudiantes. Con anterioridad a la Guerra Civil, la mayor parte de la élite intelectual de mujeres progresistas estuvo en contacto con esta institución, a través de los cursos y las conferencias que se impartieron en ella.

El Lyceum Club Femenino Español fue fundado en 1926 a imagen del Lyceum Club londinense, creado en 1905, y fue quizás la más internacional y cosmopolita asociación femenina de la época. La junta directiva del Lyceum Club madrileño estaba constituida por María de Maeztu (presidenta), Beatriz Galindo y Victoria Kent (vicepresidentas), Zenobia Camprubí (secretaria), Helen Phipps (vicesecretaria), que era la directora del Instituto Internacional, y Amalia Galágarra, señora de Salaverría (tesorera). En su grupo fundador, participaron las señoras de Pérez de Ayala, Araquistain, Álvarez del Vayo, Ucelay, Besteiro, González Martínez, Ortega y Gasset, Fabra Rivas, Mesa, Maeztu, Gutiérrez (Juan de la Encina), Díez Canedo, Baroja — se supone que Carmen Monné, la mujer de Ricardo-, Caro Raggio, Baeza, Elorrieta y Marañón. Las mujeres que se casaban perdían, como vemos, hasta su propio nombre.

Durante la Segunda República, se crearon nuevas asociaciones de mujeres. María Lejárraga fundó, en 1931, la Asociación Femenina de Educación Cívica, que llegó a contar con centenares de asociadas. En 1932, se fundó la Asociación de Mujeres Antifascistas, ligada al Partido Comunista, y poco después se creó Mujeres Libres de tendencia anarquista. Estas asociaciones, que en su mayoría eran pacifistas y antimilitaristas, no pudieron evitar, sin embargo, la tragedia de la Guerra Civil.

Estos clubs y ateneos, entre ellos el Ateneo de Madrid, así como las distintas revistas dirigidas y editadas por mujeres, hicieron posible que se estableciesen 
redes de mujeres que, desde la filosofía, el arte, la educación y la literatura, contribuyeron a la formación de una sociedad diferente, al promover la incorporación de las mujeres a la educación universitaria, al trabajo extradoméstico y a la vida pública democrática. Estas asociaciones fueron fundamentales para nuestras protagonistas, pues les permitieron crear un espacio propio y, a la vez, realizar otras actividades que les ayudaban a ampliar sus horizontes intelectuales y vitales.

Judith R. Walkowitz muestra, en La ciudad de las pasiones terribles, que desde finales del siglo XIX, se produjeron una serie de cambios en las ciudades que afectaron a la moral sexual y a la reordenación del territorio urbano, cambios a los que no fueron ajenas Madrid o Barcelona, que estaban en pleno crecimiento. Las mujeres pudieron, entonces, acceder a nuevos espacios, tales como los grandes almacenes, los salones de té, los teatros, los conciertos, las asociaciones femeninas, los nuevos espectáculos públicos, en definitiva, moverse con un mayor grado de libertad (Walkowitz, 1992). A estos cambios, se sumaron otros, como la aparición del cine, de la nueva moda, el auge del deporte y el peso de las vanguardias artísticas, que contribuyeron a promover que las mujeres saliesen cada vez más de su casa.

\subsection{Un trabajo bien hecho}

Carmen, Zenobia y María Teresa, al igual que otras mujeres, entre ellas Virginia Woolf y Vanessa Bell, del grupo de Bloomsbury, se esforzaron enormemente por obtener autonomía a través del trabajo. De hecho, pertenecieron al primer colectivo femenino de la burguesía que salieron de casa, que lograron, con un tesón fuera de lo común, tener, como dice Zenobia expresivamente, una doble vida. Carmen afirma que todo el trabajo que realizó desde muy joven fue para vencer el descontento y la tristeza que le provocaba el mundo mezquino y estrecho que la rodeaba. A partir de 1903, se dedicó a la orfebrería y llegó a obtener medallas por sus trabajos en las exposiciones de bellas artes de 1907 y 1910. Pero, como nadie de su entorno se tomaba en serio su deseo de ser una buena artista y artesana, terminó abandonando este trabajo para realizar lo que se esperaba de ella: casarse y dedicarse durante algunos años al cuidado de la casa, de los hijos y del marido. A partir de 1925, sin embargo, logró romper con esa situación gracias a dos iniciativas que cambiaron su vida: el Mirlo Blanco, un proyecto teatral en el que participó con sus hermanos y sus amigos, que se dedicaron a montar obras teatrales en casa de los Baroja, y la puesta en marcha del Lyceum Club.

Amparo Hurtado dice, en el prólogo a Recuerdos de una mujer de la generación del 98, que el Lyceum constituyó un acicate para Carmen, no solo porque dirigía la sección de Artes y colaboraba en sus actividades, sino también porque le permitió entrar en contacto, en el año 1927, con el catedrático de etnografía, folklore y artes populares Luis de Hoyos Sainz, cercano a la ILE (Hurtado, 1998). Este catedrático estaba realizando una investigación científico-histórica para catalogar piezas para el Museo Histórico Textil, al que se incorporó Car- 
men. De este modo, pudo dedicarse al estudio de la orfebrería y de las artes decorativas desde una nueva perspectiva. Fruto de ese trabajo, fue su libro $E l$ encaje en España. En 1934, el Ministerio de Instrucción Pública y Bellas Artes la nombró miembro del comité ejecutivo del Patronato del Museo del Pueblo Español, que presidía Gregorio Marañón, lo que le permitió seguir colaborando con Hoyos Sainz hasta que estalló la guerra.

Zenobia también había colaborado, cuando era joven, con la Residencia de Señoritas y con el Lyceum Club, del que fue secretaria. Publicó, en inglés y en castellano, algunos relatos cuando era adolescente, y ya en su juventud tradujo una parte importante de la obra de Tagore, al menos 18 libros. Pero, además, movida por el afán de llevar una vida activa y tener la independencia económica de la que hacían gala las mujeres de su familia que vivían en Estados Unidos, abrió, en 1928, una tienda de venta y exportación de artesanía en Madrid, que denominó Arte Popular Español. Se dedicó también a decorar casas en el barrio de Salamanca que alquilaba a diplomáticos y visitantes extranjeros, sobre todo estadounidenses. Además, dirigió la decoración del Parador Nacional de Gredos, el primero que se inauguró en 1931. Y, en colaboración con algunos amigos, dirigió la del parador privado de Ifach en Alicante (Palau de Nemes, 2006).

María Teresa se dedicó desde muy joven a escribir, porque «sus días eran largos, fríos y solos» (León, 1999: 166). Colaboró asiduamente con el Diario de Burgos, en donde firmaba con pseudónimo. La firma con pseudónimo era frecuente entre las mujeres de la época y muestra lo difícil que les resultaba poder expresarse libremente. Es conocido el caso de María Lejárraga, que firmaba con el nombre de su marido. En 1930, María Teresa regresó a Madrid, en donde había pasado su infancia, conoció a Rafael Alberti, se enamoraron y, en la Segunda República, cuando el divorcio fue posible, se separó de su primer marido y se casó con Rafael.

Las tres continuaron trabajando durante la guerra, el exilio y la posguerra, pese a las situaciones tan difíciles por las que pasaron y pese a las múltiples penalidades que sufrieron.

Carmen Baroja y Nessi estuvo, durante la guerra, en Itzea, la casona que tenían los Baroja en el País Vasco, y allí no sólo se convirtió en una labradora ejemplar para poder sostener a su familia, sino que también hizo de enfermera y siguió escribiendo, pues colaboró, desde 1938, con la revista literaria Mujer. Pero, además, a lo largo de esos años, realizó algunos trabajos que aún siguen inéditos: una comedia ligera titulada La Frivolidad, en tres actos; varias narraciones; una nouvelle, y dos guiones de cine, basados en novelas de Pío Baroja: La Feria de los discretos y Las noches del Buen Retiro. Otros trabajos salieron a la luz, entre ellos un cuento que escribió para Ricardo, su hijo pequeño, titulado Marianito, el de la Casa Grande, que se publicó en 1942. Cuando volvió a Madrid, al terminar la guerra y tras la muerte de su marido, recuperó, en 1943, su trabajo en el Museo del Pueblo Español. Continuó escribiendo un libro sobre amuletos y talismanes, redactó sus Recuerdos y publicó con frecuencia artículos en la prensa, especialmente en La Nación, de Buenos Aires. En 1945, 
publicó el Catálogo de la colección de amuletos y, en 1948-1952, el Catálogo de la colección de pendientes, cuando ya su hijo Julio Caro Baroja dirigía el Museo. En 1949, terminó Amuletos mágicos y joyas populares, un trabajo que no llegó a publicarse (Hurtado, 1998). Murió en 1950. La editorial Pamiela publicó, en 1995, un libro de poesía suyo, titulado Tres Barojas: Poemas. Carmen, además de realizar y publicar trabajos antropológicos, se sirvió de variados registros literarios, pues escribió artículos, cuentos, su autobiografía, una comedia, guiones de cine y poesía.

Zenobia, una vez exiliada, ya no regresó a España. Al principio, pasó casi dos años en La Habana (desde 1937 hasta 1939), para luego ir a Estados Unidos, en donde vivían sus hermanos con sus familias respectivas, así como parientes de su madre. En los EEUU vivieron ella y su marido Juan Ramón Jiménez hasta 1951. En todos esos años, ayudó a Juan Ramón en sus trabajos, le pasaba sus escritos a máquina, además de hacerse cargo de toda la correspondencia, de las publicaciones y los derechos de las obras y de gestionar sus vidas. Fue una mujer enormemente activa. Ella misma dice que tenía excesiva energía, lo que le permitió participar en múltiples actividades culturales y de carácter social.

En mayo de 1941, Zenobia y Juan Ramón se desplazaron, por problemas de salud de éste, desde Miami, donde residían, hasta el hospital de la Universidad de Duke, en Carolina del Norte. Y, dado que la estancia hospitalaria de Juan Ramón se prolongaba, Zenobia comenzó a asistir a cursos sobre la tragedia griega, la historia de América del Sur, la literatura francesa y la lengua italiana. Adquirió, en ese momento, la formación universitaria que tanto había echado de menos cuando era joven. En 1943, la Universidad de Maryland le propuso un puesto de profesora, así que se trasladaron a Washington y se incorporó al Departamento de Lengua y Literaturas Extranjeras. Se cumplió, así, uno de sus sueños, volver a trabajar fuera de casa, pero no el de tener «una habitación propia» donde poder estar, trabajar y escribir, una reivindicación que se mantiene a lo largo de sus tres diarios.

Escribió sus diarios durante los años de exilio. En el correspondiente a su estancia en los Estados Unidos, dice que trabajó mucho con Juan Ramón antes y después de las clases. Y que esas horas eran las más felices para ella. Pero, al final, por problemas de Juan Ramón con el idioma inglés, terminó sacrificando su carrera y sus redes familiares y se fueron a Puerto Rico, en donde, pese a enfermar de cáncer, siguió trabajando infatigablemente, sobre todo ayudando a poner en marcha la sala que la Universidad quería dedicar al poeta (en la actualidad, esa sala, convertida en museo, lleva el nombre de ambos). Los dos murieron en Puerto Rico: Zenobia, en 1956 y Juan Ramón, dos años más tarde².

2. Zenobia y Graciela Palau de Nemes fueron las principales artífices de que le fuera concedido el Premio Nobel a Juan Ramón. Fueron ellas quienes pidieron, a las universidades estadounidenses en las que el poeta había trabajado, que le presentasen al Nobel. Conviene recordar que las universidades españolas, bajo el franquismo, no lo apoyaron. 
María Teresa se afilió con Rafael Alberti, en 1933, al Partido Comunista. Durante esos años, escribió artículos, poesía, cuentos y novelas. Sus colaboraciones más importantes se publicaron en la revista El Mono Azul, pero también escribió en otras publicaciones, como Octubre o Ayuda, y en el suplemento semanal del periódico La Solidaridad, que dirigió durante algún tiempo. Fue secretaria de la Alianza de Intelectuales Antifascistas para la Defensa de la Cultura, que ella misma contribuyó a fundar y que se convirtió en un lugar de encuentro de escritores, políticos, pintores, poetas, músicos y actores, tanto españoles como extranjeros.

La Junta de Conservación y Protección del Tesoro Artístico, fundada en 1936, asignó a María Teresa toda una serie de tareas, entre ellas, custodiar los cuadros del Greco que estaban en Toledo, así como los objetos y los cuadros que peligraban en el Escorial, además de ayudar a evacuar los cuadros del Museo del Prado. Fue, además, nombrada vicepresidenta del Consejo Nacional del Teatro por el Gobierno republicano. Una de sus funciones consistió en dirigir el Teatro de la Zarzuela, en donde se representaron numerosas obras del llamado "teatro revolucionario", algunas dirigidas por ella.

Cuando las tropas franquistas tomaron Madrid, Rafael y María Teresa se vieron obligados a emprender el exilio. Llegaron a París, pero terminaron marchando a Argentina, en donde vivieron más de veinte años. Posteriormente, residieron en Roma unos cuantos años y, tras la muerte de Franco, volvieron a Madrid, en dónde María Teresa murió en 1988.

La producción literaria de María Teresa continuó creciendo en los años del exilio, pues escribió obras de teatro, novelas, guiones de cine e hizo traducciones. En sus escritos, como muy bien afirma Juan Carlos Estébanez, «la mujer se convierte en uno de los temas recurrentes», incluso desde sus primeros cuentos (Estébanez, 2003: 58). Y, tras la guerra «la biografía de doña Jimena es un homenaje a las mujeres que sufrieron las consecuencias de la guerra y el exilio. En sus guiones cinematográficos y radiofónicos, en sus novelas, en sus artículos literarios, la defensa de los valores de la mujer ocupa siempre un lugar importante» (Estébanez, 2003: 58). María Teresa León escribió otras obras sobre mujeres, pues, además de la biografía novelada de Doña Jimena Díaz de Vivar, se ocupó de Las peregrinaciones de Teresa o de El gran amor de Gustavo Adolfo Bécquer. En su último gran libro, Memoria de la melancolía, seguía preocupada por encontrar caminos para una mayor autonomía de las mujeres.

\section{Las vanguardias artísticas y la cultura popular}

El 21 de diciembre de 1879, el dramaturgo noruego Henrik Ibsen estrenaba Casa de muñecas, una obra en la que la protagonista, Nora, una mujer de clase media casada con un banquero, rompía con su cobarde marido y abandonaba el hogar burgués. El estreno de la obra en los diferentes países europeos iba sistemáticamente acompañado de vivos enfrentamientos y polémicas. En el mundo de la escena, la primera gran réplica a Ibsen vino de la mano de otro dramaturgo, en este caso sueco: August Strindberg. En 1888, Strindberg escri- 
bió tres obras contra su compañero de profesión, Ibsen, en las que ponía de manifiesto sus concepciones misóginas: El padre, La señorita Julia y Acreedores. En esta última, el objeto de sus ataques ya no era simplemente Nora, era también el artista que la apoyaba y se convertía en su amigo y compañero.

Nuestras tres protagonistas fueron amantes de la literatura, el teatro, la música, la pintura y la poesía. No solo pertenecieron a asociaciones de mujeres, sino que también se movieron en unas redes sociales muy amplias, unas redes ligadas sobre todo a la literatura y las artes, pero también a la política, la filosofía, la historia e hicieron de la lengua su segunda casa. Al igual que otras mujeres de la edad de plata, entre las que se encuentran María de Maeztu, Margarita Nelken, Carmen de Burgos, María Martínez Sierra, Maruja Mallo, María Zambrano, Victoria Kent, Rosa Chacel, Clara Campoamor o Ángeles Santos, denunciaron las funciones que les eran asignadas $y$, al romper con ellas en la práctica, se hicieron acreedoras a críticas por parte de las fuerzas conservadoras. Muchas de ellas se vieron forzadas al exilio.

En el caso de mujeres de la burguesía, disconformes con su destino, el desarrollo de una determinada sensibilidad estética desempeñó un papel nada desdeñable para poder romper con su estatuto de minoría. La pasión de nuestras protagonistas por las artes y las letras estuvo vinculada a la importancia que entonces cobraron los movimientos vanguardistas. La ruptura con los cánones estéticos heredados, el rechazo de la tradición de la que hacían gala las academias, la aproximación a una bohemia artística y literaria permitió a muchas mujeres cuestionar el valor de la moral recibida de sus padres, una moral católica, pacata y puritana, acorde con la defensa del injusto orden social reinante. La frecuentación de algunos medios artísticos y literarios, así como los viajes, las tertulias y las exposiciones, les facilitaron el encuentro con un mundo cosmopolita en el que abundaban los debates y las conversaciones sin censura.

La participación en círculos progresistas y la búsqueda de experiencias estéticas rupturistas hicieron también que bastantes mujeres, y en todo caso Carmen, Zenobia y María Teresa, se interesasen por la cultura popular. Las tres fueron sensibles a la creatividad de las culturas populares y a la urgencia de conservar sus producciones. Por otra parte, la falta de títulos universitarios y los propios trabajos oficialmente considerados femeninos contribuyeron a aproximarlas al mundo de la artesanía y del trabajo bien hecho. Esta conexión con las culturas populares, aunque con un cierto tinte elitista, contribuyó a que conociesen la dura realidad de la sociedad española y también a hacerlas más críticas con los estilos de vida de la burguesía convencional.

Carmen, Zenobia y María Teresa, a pesar de sus ingentes esfuerzos para lograr un espacio propio, se vieron en parte invisibilizadas, como ya se ha dicho, al vivir al lado de varones reconocidos. Carmen vivió en la misma casa que sus hermanos Pío y Ricardo Baroja hasta que este último se casó con Carmen Monné; Zenobia pasó gran parte de su vida a la sombra de Juan Ramón Jiménez, y María Teresa, a la de Rafael Alberti. Todos ellos no solo fueron varones famosos, sino que dieron muestras de poseer un alto grado de narcisismo. Pero a este eclipse se sumó la larga noche del franquismo, que supuso, 
sobre todo en las dos primeras décadas, el triunfo del nacional-catolicismo y del fascismo, la militarización de la sociedad y del pensamiento. Para las mujeres progresistas desterradas, el exilio supuso el silencio, la censura de sus escritos, la muerte social. Y para muchas de las que se quedaron, el exilio interior, las dificultades para seguir con su vida profesional, como pone bien de relieve, por ejemplo, la vida de María Moliner, y en cierta medida la de la propia Carmen Baroja. Se instauraba de nuevo un proceso de vuelta al hogar y de sometimiento de las mujeres orquestado por una iglesia omnipresente, por la Sección Femenina y por el régimen dictatorial. La acción conjunta de los diferentes agentes de la moral instituida no dejaba espacio para la existencia de modos de vida alternativos y reflexivos.

\section{Reflexiones finales: el capital altruista, una nueva dimensión del capital social}

Nuestras protagonistas muestran, a través de sus relatos autobiográficos, una gran fuerza, que proviene en buena medida del ambiente en el que se criaron, del capital económico, cultural y social que recibieron, así como también de su defensa de la democracia y de la paz.

A lo largo de este artículo, se ha puesto de manifiesto que echaron de menos el acceso a una educación universitaria, que se esforzaron por conseguir un trabajo profesional y que se apoyaron en asociaciones de mujeres y en una vanguardia artística vinculada con la crítica cultural para romper el cerco en el que se las pretendía encerrar. Lograron, así, como decía Zenobia, llevar una doble vida, es decir, ocuparse de la casa y, al mismo tiempo, poder realizar actividades fuera de ella, aunque el espacio de la política les seguía estando prácticamente vedado. Con la llegada de la Segunda República, muchos de sus afanes se vieron materializados, ya que hubo cambios importantes en las leyes, la educación, el trabajo y la política. El franquismo supuso, en este sentido, un retroceso enorme para la emancipación de las mujeres, de tal modo que la generación de la transición a la democracia se encontró luchando de nuevo por recuperar las conquistas abolidas por la dictadura. Se produjo, así, una situación bastante afín entre la generación de las mujeres de la transición y la de Carmen, Maria Teresa y Zenobia. Una vez más, fue importante el desarrollo del capital social, así como las asociaciones de mujeres que lucharon por la transformación de las leyes, los derechos vinculados al trabajo y el acceso a la educación universitaria y al campo político. Se puede decir que, en la actualidad, las mujeres han logrado un mayor equilibrio de poder con los varones, y están representadas en múltiples ámbitos del espacio público, resultado de los esfuerzos conjuntos realizados por las feministas, especialmente durante las décadas de 1970 y 1980. Pero nada es irreversible históricamente. No existe un progreso lineal, y el peligro de la involución sigue estando presente. De ahí que convenga subrayar, en el legado de nuestras tres protagonistas, la importancia de desarrollar el capital social a través de asociaciones, clubs culturales, ateneos y encuentros, que permitieron tejer con mayor fuerza los lazos sociales y profundizar en la democracia. 
La mirada propia de la sociología histórica sirve para hacernos más sensibles a la dimensión social de las trayectorias vitales, para poder considerar a las mujeres seres sociales en el pleno sentido de la palabra. A lo largo del trabajo, he tratado de sintetizar, en el nuevo concepto de capital altruista, las acciones solidarias de estas tres mujeres, que les han permitido romper, en parte, con el dispositivo de feminización. Las diferentes modalidades de poner en marcha este capital no son ajenas a la posesión de los otros tipos de capital que no sólo pudieron ejercitar con las personas que se movían en sus círculos próximos, sino también con aquellos que estaban en situaciones vulnerables, ya fuesen los niños de la guerra, los presos de la dictadura o los soldados heridos (Varela, 2011). Lograron, así, mantener un fructífero equilibrio inestable entre el nosotros y el yo, y pudieron desarrollar una ética que implica que el buen cuidado de uno mismo no es posible si no está vinculado al cuidado de los otros, tal y como puso de relieve Michel Foucault en la Hermenéutica del sujeto (Foucault, 1994).

El capital altruista aparece especialmente ligado en Carmen, Zenobia y María Teresa, a la fuerte sociabilidad que desarrollaron, a los diferentes círculos en los que se movieron, a su aprecio por los valores artísticos y literarios, así como a su preocupación, coincidiendo con la generación del 98, por la regeneración de España. Pudieron también desarrollar este capital porque asumieron una tradición democrática que es preciso rescatar si se quiere romper con la falta de reconocimiento que afecta a la vida y a la obra de muchas mujeres. ${ }^{3}$

El capital altruista, que implica un modo solidario de entender el mundo, así como el compromiso personal, ha sido socialmente desvalorizado, por ser el principal capital de las mujeres frente al capital económico del que suelen hacer gala los varones, pero también por la fuerte pujanza que están teniendo en las últimas décadas el neoliberalismo y el comunitarismo conservador. El altruismo es incompatible con el capitalismo voraz, el capitalismo financiero. El neoliberalismo afirma la primacía del mercado para regular la vida social y promueve un individualismo egoista, por utilizar las palabras de Émile Durkhe$\mathrm{im}$, mientras que el comunitarismo conservador insiste en la importancia de los vínculos sociales, pero lo hace volviendo a sacralizar la familia tradicional, lo que implica aceptar el retorno de las mujeres al hogar doméstico y las presiones de la comunidad en tanto que factor de control social. De este modo, el auge del Homo economicus y del comunitarismo conservador están contribuyendo, en la actualidad, a la conformación de una sociedad cada vez más desigual e injusta y a la existencia de sujetos cada vez más frágiles. Es, por lo tanto, fundamental, para la calidad de vida, para la riqueza de las relaciones sociales y, en fin, para llevar una vida digna en una sociedad de iguales, una sociedad de ciudadanas y ciudadanos, no solo sacar a la luz la sensibilidad, la imaginación, los saberes, las prácticas y la voluntad de muchas mujeres por encontrar un espacio propio, sino también recuperar el capital altruista, así como una tradición democrática y laica que hemos heredado del pasado.

3. Para ampliar información sobre estos aspectos puede consultarse el libro Mujeres con Voz propia (Varela, 2011). 


\section{Referencias bibliográficas}

BAROjA y Nessi, Carmen (1998). Recuerdos de una mujer de la generación del 98. Barcelona: Tusquets. Edición, prólogo y notas de Amparo Hurtado.

Bourdieu, Pierre (2000). La dominación masculina. Barcelona: Anagrama.

Burgos, Carmen de (2007). La mujer moderna y sus derechos. Valencia: Editorial Sempere / Ayuntamiento de Madrid, 1927.

Camprubí Aymar, Zenobia (1986). Vivir con Juan Ramón Jiménez. Madrid: Los Libros de Fausto. Anaquel de los Recuerdos, 2.

- (2006a). Diario 1. Cuba (1937-1939). Madrid: Alianza. Edición, traducción, introducción y notas de Graciela Palau de Nemes.

- (2006b). Diario 2. Estados Unidos (1939-1950). Madrid: Alianza. Edición, traducción, introducción y notas de Graciela Palau de Nemes.

- (2006c). Diario 3. Puerto Rico (1951-1956). Madrid: Alianza. Edición, traducción, introducción y notas de Graciela Palau de Nemes.

- (2006d). Epistolario 1. Cartas a Juan Guerrero Ruiz 1917-1956. Madrid: Amigos de la Residencia de Estudiantes.

Caro Baroja, Julio (1997). Los Baroja: Memorias familiares. Madrid: Caro Raggio.

CASTEL, Robert (1977). «Une approche non évolutioniste du changement social». En: Rotmann, R. (dir.). Au risque de Foucault. París: Éditions du Centre GeorgesPompidou, 161-169.

— (1995). «Michel Foucault et l'histoire du présent». En: Hatchuel, A. (1997). Las metamorfosis de la cuestión social. Buenos Aires: Paidós.

Claramunt, Teresa (1905). La mujer: Consideraciones sobre su estado ante las prerrogativas del hombre. Mahón: El Porvenir del Obrero.

Domínguez PRATS, P. (2009). De ciudadanas a exiliadas: Un estudio sobre las republicanas españolas en México. Madrid: Cinca.

Elias, Norbert (1984). La sociedad cortesana. México: Fondo de Cultura Económica.

- (1994). «El cambiante equilibrio de poder entre los sexos. Estudio sociológico de un proceso: el caso del Antiguo Estado Romano». En: Conocimiento y poder. Madrid: La Piqueta.

EstéBAnEz GiL, Juan Carlos (2003). María Teresa León: Escritura, compromiso y memoria. Burgos: Fundación Instituto Castellano y Leonés de la Lengua.

Foucault, Michel (1994). «Ética del cuidado de sí». En: Hermenéutica del sujeto. Madrid: La Piqueta, 105-142.

- (1999). Historia de la sexualidad, Vol. I. La voluntad de poder. Barcelona: Paidós.

GEMIS, Vanessa (2008). «La biographie genrée: le genre au service du genre». COnTEXTES, 3.

GIDDENS, Anthony (1995). Las transformaciones de la intimidad. Madrid: Cátedra.

Gustavo. Soledad (1896). A las proletarias. Buenos Aires: La Questione Sociale.

- (1899). La sociedad futura. Barcelona: Ediciones de La Revista Blanca.

Hatchuel, A.; Pezet, É.; STARKey, K. y Lenay, O. (2005). Gouvernement, organisation et gestion: L'héritage de Michel Foucault. Québec: Les Presses de l'Université Laval, 51-61.

Hurtado, Amparo (1998). «Prólogo». En: Baroja y Nessi, Carmen (1998). Recuerdos de una mujer de la generación del 98. Barcelona: Tusquets.

LeÓn Goyri, María Teresa (1999). Memoria de la melancolía. Madrid: Castalia. Edición y prólogo de Gregorio Torres Nebrea.

MANGINI, Shirley (2001). Las modernas de Madrid: Las grandes intelectuales españolas de la vanguardia. Barcelona: Península. 
Mujeres en la Transición Democrática (1999). Españolas en la transición: De excluidas a protagonistas (1973-1982). Madrid: Biblioteca Nueva.

NASH, Mary (1999). Rojas: Las mujeres republicanas en la guerra civil española. Madrid: Taurus.

NASH, Mary y FERRANDIS, Marisa (1991). «Dos décadas de la historia de las mujeres en España: Una reconsideración». Historia Social, 9, 137-161.

NeLKEN, Margarita (1975). La condición social de la mujer. Su actual estado: su posible desarrollo. Madrid: Ediciones CVS, 1919.

Palau de Nemes, Graciela (2006). «Introducción». En: CAMPrubí Aymar, Zenobia (2006). Diario I. Cuba (1937-1939). Madrid: Alianza.

SOMBART, Werner (1979). Lujo y capitalismo. Madrid: Alianza.

TAVERA, Susana (coord.) (2000). Mujeres en la historia de España: Enciclopedia biográfica. Barcelona: Planeta.

VARELA, Julia (1997). Nacimiento de la mujer burguesa: El cambiante desequilibrio de poder entre los sexos. Madrid: La Piqueta.

- (2011). Mujeres con voz propia. Madrid: Morata.

VARIKAS, Eleni (1983). «L'approche biographique dans l'histoire des femmes». Les cahiers du GRIF, 37-38, primavera, 41-56.

VVAA (1994). Textos para la historia de las mujeres en España. Madrid: Cátedra.

WALKOWITZ, Judith (1992). La ciudad de las pasiones terribles. Madrid: Cátedra. 